\title{
Co-criação como estratégia de aprimoramento do projeto Tear Terapia
}

\section{Co-creation as a project improvement strategy}

SAVI, Catherine; Graduanda; Universidade do Sul de Santa

Catarina; catherinesavi29@gmail.com

SILVA, Claudio; Doutor; Universidade do Sul de Santa

Catarina; design@midiak.com.br

\section{Resumo}

O papel das ONG's no Brasil e no mundo é de total importância uma vez que atendem diversas demandas da sociedade. A ONG e Associação João Paulo II, na Ponte do Imaruim, Palhoça/SC, foi fundada no intuito de ajudar a comunidade e atualmente passa por considerável dificuldade financeira. Com o objetivo de contribuir para geração de renda da associação, foi aplicada a metodologia do HDC (Design Centrado no Ser Humano) para aprimorar o projeto de artesanato Tear Terapia desenvolvido por ela. Também foram aplicadas ferramentas do co-design e identificadas a relação entre design e artesanato. Visou-se compreender o âmbito social do Design e a relevância da gestão de design dentro de projetos comunitários. O trabalho desenvolvido junto ao projeto Tear Terapia fez com que as voluntárias se envolvessem durante o processo e consequentemente pôde contribuir para a continuidade das ações da Associação.

Palavras Chave: design; artesanato; co-criação, gestão de design.

\begin{abstract}
The role of ONGs in Brazil and in the world is totally because they meet the various demands of society. An ONG and an Association of John Paul II, at Ponte do Imaruim, in Palhoça / SC, was founded in order to help the community and become a great financial goer. In order to contribute to the generation of resources, the HDC (Human Centered Project) methodology was applied to the Tear high quality craft project developed by it. Co-design tools and a relationship between design and craftsmanship were also used. The aim was to understand the social scope of project and project management within social projects. The Tear Therapy made the companies become, at the same time, the decision-making process of the Association Association of Actions.
\end{abstract}

Keywords: design; crafts; co-creation, design management 


\section{Artigo de Iniciação Científica}

\section{Introdução}

O processo artesanal originou-se muito antes da definição estética do belo, tanto que a história do artesanato se difunde com a história do surgimento do homem. Os primeiros artesãos surgiram quando o homem aprendeu a polir a pedra, a fabricar a cerâmica e a tecer fibras naturais. No Brasil, os índios são considerados os primeiros artesãos. Eles praticavam a pintura, usando pigmentos fabricados a partir de elementos da natureza, técnicas de cestaria e cerâmica, e até mesmo a criação dos cocares e tangas feitas com penas e plumas de aves.

Segundo Canclini (1982, p.93), dentro do cenário nacional, o artesanato é visto como parte da cultura material brasileira, sendo assim, pode ser considerado um elemento de fortalecimento da identidade do país. Os artefatos desenvolvidos adquirem significados particulares, refletindo os valores e as referências culturais nacionais "por se tratarem de objetos, técnicas de produção e desenhos que estão enraizados na própria história destes povos".

Atualmente é possível reconhecer que o artesanato é uma fonte de renda para muitas famílias e organizações. Dos 9,2 milhões de desempregados no Brasil, 3,3 milhões pertencem ao emprego informal e cerca da metade deste contingente é composto pelo sexo feminino. $O$ artesanato é uma das principais atividades recorridas por estas pessoas (GUEDELHA, 2008). Dessa maneira é possível reconhecer os diversos propósitos das atividades artesanais.

No município de Palhoça/SC, existe o bairro Ponte do Imaruim, nele concentra-se uma parcela significativa de pessoas com dificuldades de alimentação, higiene, saúde, habitações decentes, ou seja, uma região empobrecida. A Associação João Paulo II, fundada em 1980, com o objetivo de atender crianças e jovens da comunidade, recebe em período integral 180 crianças de baixa renda com idade entre 2 a 15 anos. No local são oferecidas aulas de música, tear, informática e turmas de alfabetização para adultos. Além da realização de atividades sociais, culturais e esportivas, em linha de desenvolvimento comunitário. A associação necessita de recursos financeiros para se manter, porém, sofre com grandes dificuldades de arrecadação. Há um eminente desejo de que ela tenha atividades que a tornem autossustentável.

Uma das iniciativas existentes na associação é o Tear Terapia. Trata-se de um grupo de mulheres voluntárias que produzem peças artesanais, a partir do tear manual. Os produtos confeccionados são vendidos para ajudar a associação financeiramente. Porém a ausência de planejamento faz com que haja significativa dificuldade de engajamento e autonomia das voluntárias, além do baixo fluxo de vendas dos produtos feitos. Em suma, observa-se que há falta de direcionamento e gestão. Dessa forma, o design pode vir, para contribuir de maneira positiva para associação e comunidade local. Para Mozota (2011) a gestão de design tem como função identificar e comunicar como o design pode contribuir com o valor estratégico de uma organização, integrando a gestão em nível operacional do projeto (ação), organizacional ou tático (função) ou estratégico (missão).

É necessário fazer com que o design tenha um papel social, ajudando na solução de problemas. Então, diante da necessidade que a Associação João Paulo II tem de geração de renda, considerou-se convidar as voluntárias a colaborarem com ideias no projeto. Assim, auxiliando para que suas necessidades sejam atendidas para poderem prosseguir de maneira sustentável e independente. Em suma, o objetivo do projeto foi aprimorar o projeto Tear Terapia por meio da cocriação. 
O Design propicia a oportunidade de atender as necessidades dos usuários por meio de cooperação, envolvimento, inclusão, abertura e transparência. Por meio da metodologia do HCD (Design Centrado no Ser Humano), espera-se uma contribuição do Design de maneira que as ferramentas utilizadas sejam compreendidas pelos usuários e que sejam caracterizadas suas reais necessidades. $O$ usuário como parte integrante e ativa do projeto, co-criando, pode possibilitar um maior envolvimento além do incentivo à aproximação das famílias com a associação. Além da importância da realização de atitudes que gerem autonomia e comprometimento entre a associação e a comunidade. Com o propósito de que se possa contribuir de maneira benéfica, incentivando movimentos que englobem tanto o usuário, quanto suas necessidades e áreas do design que possam ajudá-lo a atingir seus objetivos.

\section{Metodologia de Projeto}

Buscando atender aos procedimentos técnicos e implantação do projeto, adotou-se a metodologia do HDC (Design Centrado no Ser Humano), idealizado pela IDEO (2009), a co-criação. Um processo que permite criar junto, podendo vincular o design ao artesanato.

Figura 1 - As etapas do HCD

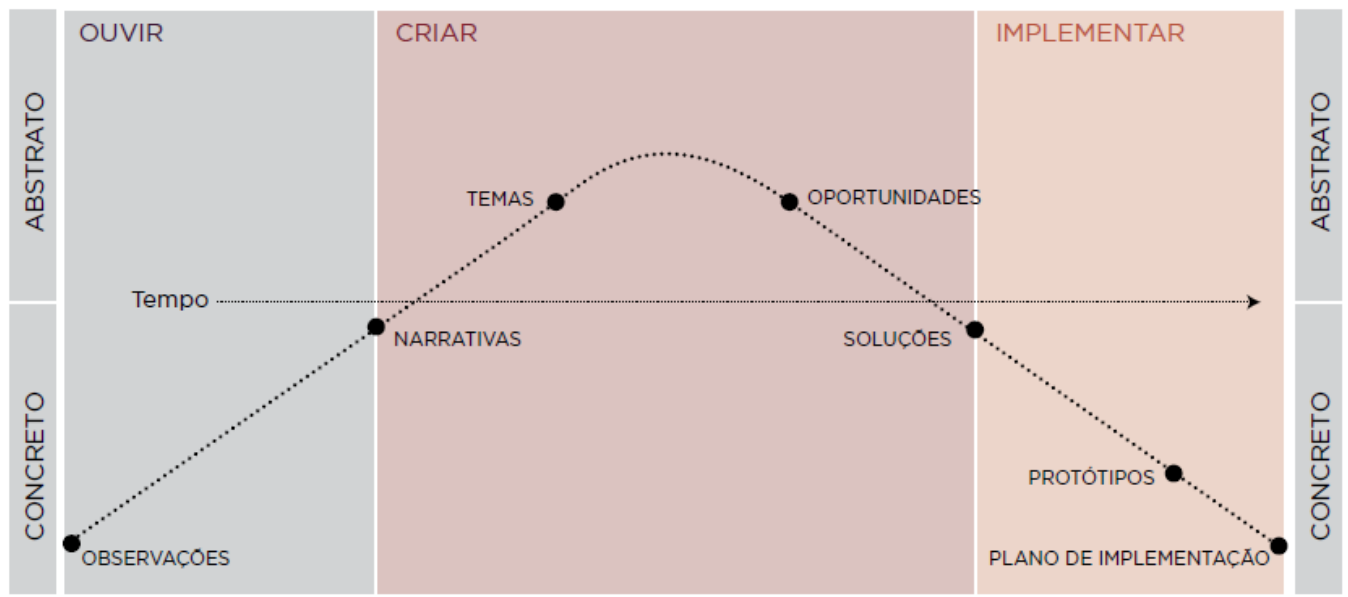

Fonte: IDEO (2009)

O HCD foi aplicado como uma abordagem dentro do projeto de design por meio da aplicação de métodos e técnicas. Patnaik e Becker (1999, p.37-43) afirmam que a metodologia do HCD tem como alvo conhecer em nível profundo as atividades dos usuários e seus significados, assim como suas crenças, preferências, emoções, motivações, dificuldades, ambientes, e interações com produtos. Sendo assim, mostrou-se uma metodologia plausível de ser praticada para o aprimoramento do Projeto Tear Terapia.

Cada uma das etapas do HCD (Ouvir, Criar e Implementar) são melhores descritas adiante, juntamente com a apresentação de métodos/técnicas utilizadas e resultados obtidos. 


\section{Design, artesanato e co-criação}

Para este projeto foi necessário compreender a respeito da relação entre design e artesanato. Serafim (2015) enfatiza que o Design, ao entrar no mundo do artesanato, propiciou o surgimento de um novo cenário, valorizando a tradição através de um olhar contemporâneo. Além de que salienta relevantes ações e projetos de Design relacionados ao artesanato. Onde a busca pela compreensão de diferentes modos de atuação do designer junto a grupos artesanais, permitiu verificar diversas possibilidades de configuração, considerando parâmetros similares onde todas são de vantagem simultânea para ambas as partes.

Segundo BORGES (2011, p.129) os designers podem atuar no artesanato em pontos como:

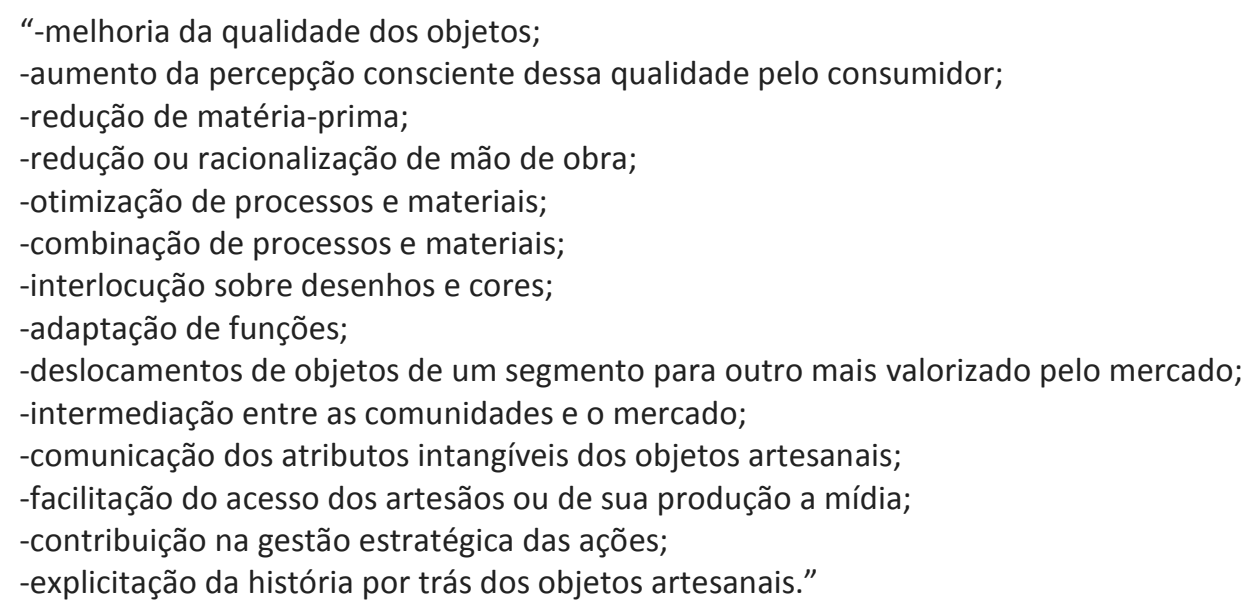

(BORGES, 2011, p 129)

Além de compreender também o co-design e suas aplicações, com a finalidade de ter uma criatividade coletiva mais bem-sucedida. Os autores Sanders e Stappers (2008) defendem a cocriação como qualquer ato de criatividade coletiva, ou seja, criatividade compartilhada por duas ou mais pessoas. Os autores ressaltam que o co-design se refere à criatividade de designers e pessoas não treinadas em design trabalhando em conjunto no processo de desenvolvimento do projeto.

Para Muzake e Vilamil (2012) co-design pode ser definido como:

\footnotetext{
"Co-design refere-se amplamente ao esforço para combinar as opiniões, insumos e habilidades de pessoas com muitas perspectivas diferentes para resolver um problema específico. Facilitador, pois, orienta a co-criação, incentivando a participação e capacitando a comunidade para enfrentar seus problemas com suas próprias soluções. Ativista, pois, ajuda a fazer as boas ideias existentes, mas ninguém sabe como aplicar. E criador pois usa suas habilidades criativas de forma colaborativa." (MUZAKE e VILAMIL, 2012, p. 7, tradução nossa)
}

A abordagem do co-design foi usada com o objetivo de que os produtos confeccionados possam atender melhor às demandas, consigam transmitir todo o trabalho realizado pelas voluntárias e que desse modo possa contribuir para que haja maior comercialização. A relevância de co-criar com essas mulheres, baseia-se em projetar "com" elas e não apenas "para". Há geração de conhecimentos, caracterizados pela junção do saber local da comunidade com o conhecimento científico, resultando numa construção de conhecimento social. 
Além de salientar a importância da gestão do design dentro de projetos que visam crescimento. Onde segundo Mozota (2003), o Design se torna um processo interno de gestão, uma atividade que integra e coordena setores organizacionais como a pesquisa de mercado, a estratégia de marketing, branding, planejamento, desenvolvimento de novos produtos, políticas de comunicação corporativa, produção, etc.

\section{Fase Ouvir}

Para a etapa de ouvir, foram selecionadas as ferramentas de imersão, empatia, linguagem corporal, entrevista em grupo, programa guiado e conversa informal para serem utilizadas dentro da metodologia do HCD. Esta fase é definida por ouvir e registrar exatamente o que as pessoas estão dizendo sem tirar conclusões. Trata-se de observar individualidades e padrões. Observar as pessoas tomando decisões, socializando, tendo autonomia em suas tarefas e assim aprofundando a compreensão da realidade estudada.

O grupo é frequentado por mulheres e foi observado que há uma grande empatia entre as voluntárias. Elas opinam, ajudam e elogiam o trabalho uma das outras. A maioria delas tem o artesanato como um momento de descontração e de aumento da criatividade. Todas são donas de casa e algumas se dedicam a prática do tear como hobby. Porém, o artesanato não é uma fonte de renda primária. São voluntárias no projeto pois além de o terem como terapia, sentem satisfação em poder ajudar a Associação. Os produtos confeccionados na associação têm o lucro revertido para o ensino das crianças da comunidade que estudam ali.

Contudo, há uma grande dificuldade em venderem as peças do tear. Ao questionar as voluntárias do porquê de tal dificuldade, foram relatados alguns motivos. A dificuldade começa pela falta de embasamento na hora de escolher as cores das linhas a serem utilizadas nas peças confeccionadas. E o valor elevado por conta da mão de obra além da falta de divulgação do trabalho do grupo. Dessa maneira, os produtos confeccionados acabam sendo vendidos para pessoas de dentro da própria ONG, funcionários, voluntários ou para esporádicos visitantes que a associação recebe. Outra dificuldade que o grupo enfrenta é a grande rotatividade de voluntárias.

Questionadas a respeito do que idealizam para projetos futuros, as mesmas relataram que devem aprender novas técnicas, combinações de cores e escolha de diferentes tipos de fios. Admitem que há falta de direcionamento e elementos novos dentro do trabalho realizado. Comentaram também a respeito da falta de conhecimento e experiência de como organizar os produtos para venda. Logo, não contribuindo de maneira significativa financeiramente com a associação. Mesmo com o pouco que vendem, conseguem ter um fundo de reserva próprio, para a compra de materiais como barbante e lã.

\section{Fase Criar}

Uma vez observadas diversas demandas dentro do projeto Tear Terapia, dentro das possibilidades elencadas por Borges (2011, p.129) nas quais o designer pode atuar para beneficiar o artesanato, algumas foram selecionadas para o projeto. O critério de escolha para selecioná-las foram as que poderiam atender as demandas do Tear Terapia de maneira quase que imediata. Dessa maneira, as escolhidas para o projeto do tear foram: 1 . Aumento da percepção consciente da qualidade do produto pelo consumidor; 2 . Interlocução sobre desenhos e cores; 3 . Comunicação dos atributos intangíveis dos objetos artesanais; 4. Contribuição na gestão estratégica das ações. As 
ferramentas elencadas para essa etapa do projeto foram a pesquisa desk, o brainstorming, geração de alternativas para identidade visual e tag, get visual, sessões de co-criação e coleta de feedback.

De acordo com a possibilidade do aumento da percepção de qualidade das peças produzidas pelo tear e da comunicação dos atributos intangíveis dos objetos artesanais, foi percebida a oportunidade de melhor aproveitamento da tag que acompanha as peças prontas para venda. Para que ela carregue consigo informações mais relevantes e objetivas a respeito do produto, como sua origem e finalidade da venda. Pois não se trata de um produto meramente comercial, há uma essencial por trás e que não deve ser ofuscada.

Há também a necessidade de elaboração de um adesivo para selar o plástico no qual os produtos são postos antes de serem vendidos. Dessa forma há maior segurança na embalagem para que o produto não saia da mesma. Desse modo houve a necessidade da criação de uma identidade visual para o projeto do tear terapia. Utilizou-se da ferramenta sessão de co-criação onde foi solicitado para que as voluntárias desenhassem, em 5 minutos, a primeira coisa que as vinha à mente quando pensavam no tear (Figura 2).

Figura 2 - Desenhos das voluntarias

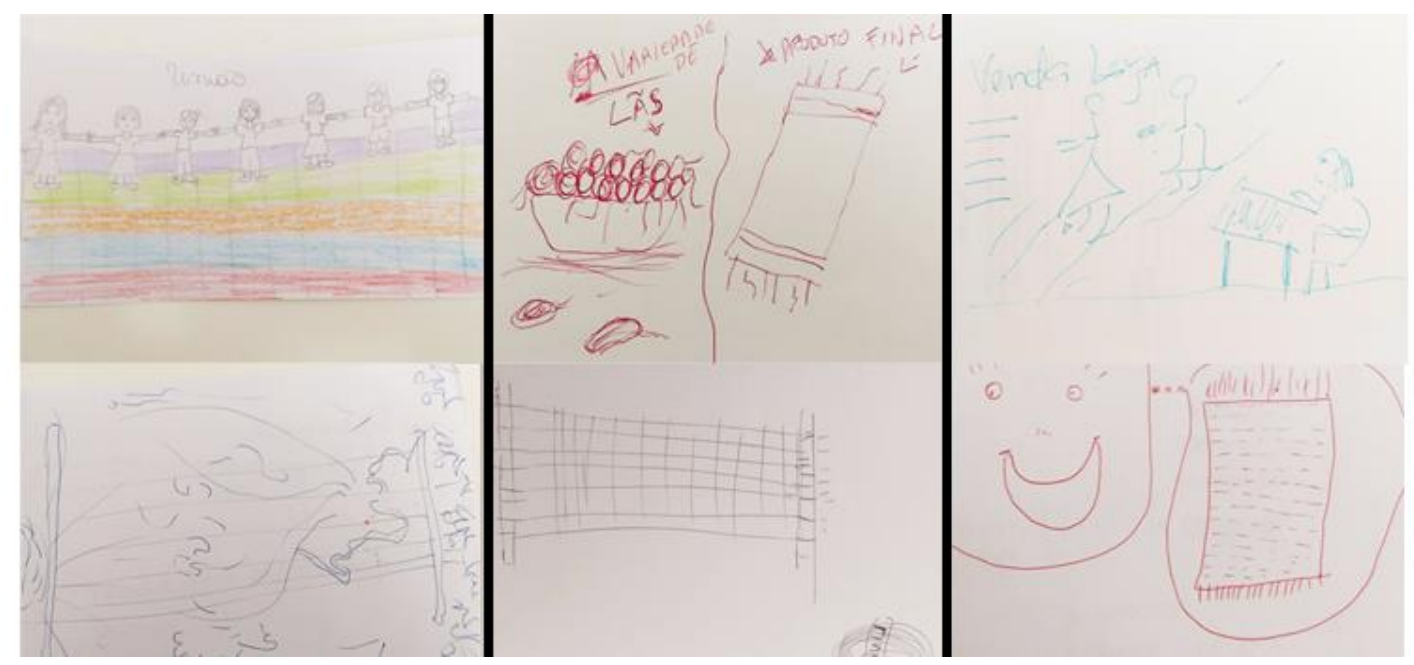

Fonte: Elaboração do Autor, 2017.

A partir dos desenhos feitos, as representações das voluntárias puderam ser refinadas e com aprimoramento foram geradas 5 alternativas de identidade visual para o projeto do tear Terapia. Dessa maneira, as voluntárias estão totalmente inclusas no processo de criação e assim foi escolhida 1 alternativa final.

Perante a possibilidade de contribuição na gestão estratégica das ações do projeto do tear, foi exercitada a ferramenta brainstorming porém houve uma grande dificuldade em sua aplicação. As voluntárias se sentiram sedentas de ideias e sentiram novamente que precisam de amparo do Design para uma intervenção positiva, a qual elas possam dar continuidade sozinhas. Considerouse, então, a possibilidade de se elaborar um planejamento de acordo com as demandas anuais. Assim, as voluntárias serão capazes de determinar suas metas de atividades de curto e longo prazo. As atividades realizadas se configuram como momentos de co-criação. 
Dentre as diversas contribuições elencadas por Borges (2011) que o Design pode promover ao artesanato, dentro do projeto Tear Terapia uma delas é a interlocução sobre desenhos e cores. Foram utilizados círculos cromáticos onde são possíveis fazer combinações análogas, monocromáticas, tríade e complementares. Essa ferramenta será associada ao planejamento anual do projeto do tear associado às estações do ano. Dessa forma, as cores de linha/lã a serem utilizadas na confecção das peças do tear também seguirão as estações, tendo uma coerência.

Em geral o feedback coletado foi muito produtivo e estimulador do interesse das voluntárias a estarem cada vez mais envolvidas ao projeto. Dessa forma, procurar compreender os objetivos que o tear terapia pretende alcançar, perceber a riqueza e criatividade embutidas no artesanato, é essencial para a atribuição de valor.

\section{Fase Implementar}

Perante a todas as possibilidades estudadas, há uma necessidade de se deixar um legado para o projeto do Tear Terapia. Mozota (2000) defende que o designer necessita deixar uma herança perante a implementação de novos processos para que, no caso, as voluntárias possam ter autonomia e dar continuidade aos aprimoramentos implementados. As ferramentas utilizadas nessa fase foram a prototipação, staff your project e coleta de feedback.

Os resultados obtidos (Figura 3) visando o aumento da percepção consciente da qualidade do produto pelo consumidor e a comunicação dos atributos intangíveis dos objetos artesanais, foi então criada uma identidade visual (1) para o projeto do Tear Terapia. A partir daí houve a criação de uma nova tag (2) para os produtos e de um adesivo (3) para as embalagens plásticas.

Para contribuir na gestão estratégica das ações do projeto do tear, foi elaborado um planejamento anual (4) das atividades do projeto Tear Terapia. Foi esquematizado de forma simples seguindo as estações do ano. Visando realizar a interlocução sobre desenhos e cores, foram desenvolvidos quadros em MDF com círculos de cores (4) um para cada estação do ano.

Figura 3 - Resultado da fase de implementação

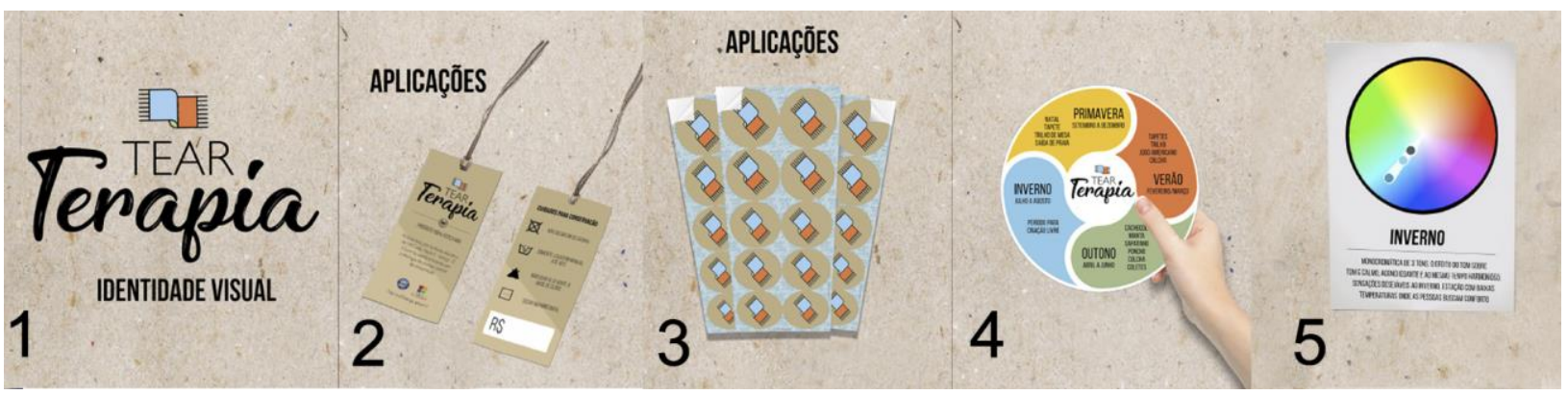

Fonte: Elaboração do autor, 2017.

Nestes quadros, os ponteiros são fixos de maneira a se movimentarem juntos e apresentam um círculo vazado para que através dele se possa ver a cor escolhida no círculo cromático. Foram produzidos quatro quadros com possibilidades diferentes de se combinar de cores a partir do conceito "estações do ano" (primavera, verão, outono e inverno). Essa definição foi feita tendo como base o planejamento anual das peças fabricadas segundo as demandas das diferentes épocas. Todos os quadros apresentam uma explicação do porquê das combinações sugeridas para cada estação. 
Dessa forma há inúmeras paletas para serem selecionadas pelas artesãs. Dentro do feedback obtido possibilitou ter conhecimento se as soluções de Design atenderam realmente as necessidades desejáveis e de maneira viável. Porém apenas a longo prazo se saberá a eficácia, mesmo as soluções propostas tendo sido muito bem aceitas e despertado nas voluntárias o sentimento de continuarem contribuindo com o projeto de maneira assídua e independente.

\section{Conclusão}

Este projeto visou desenvolver a capacidade de reconhecer que atos, mesmo que singelos, podem gerar grandes impactos na sociedade. Passar a informação de que quando pessoas se unem por uma causa, os resultados dessa união são extremamente relevantes. Visou-se valorizar o trabalho feito com as mãos, artesanato esse, fruto de dedicação e solidariedade. As artesãs não buscam nada em troca dentro da prática, sendo que para elas, a maior recompensa é ver a Associação João Paulo II em funcionamento. O que as motiva a continuarem no projeto é saber que de certa forma, elas contribuem para que a realidade, e consequentemente o futuro, de muitas crianças sejam amparados pela escola.

Toda a pesquisa teve o propósito de entender os benefícios de aliar o aspecto artesanal as contribuições que o design pode oferecer. Para isso, foram fundamentadas algumas áreas de conhecimento, realizadas pesquisas bibliográficas, aplicação da metodologia do HCD e utilização de ferramentas de Design. O uso dessa metodologia permite que haja diversas possibilidades de resultados finais. O processo começa de maneira abstrata e vai se construindo a partir de necessidades identificadas.

Desde o início do processo, salientou-se a importância da autonomia e tomadas de decisões em grupo. O designer então surge como intermediador entre necessidades e objetivos. Assim, cocriando, há um legado de conhecimento e experiências que ficarão junto às voluntárias do tear. Assim, elas conseguirão aperfeiçoar suas práticas de maneira proativa a longo prazo e podendo ser compartilhada com novas voluntárias.

Depois de todas as etapas realizadas, as possíveis transformações no segmento não finalizam. Um dos próximos encaminhamentos seria a facilitação do acesso dos artesãos a mídia. Intermediar canais para que os produtos possam ter maior acesso ao mercado. Além de um mostruário fixo para que sempre haja peças modelos na sala do tear. Outro próximo encaminhamento é orientar as artesãs de modo possam calcular o valor do seu artesanato.

Diante de todo o estudo, os resultados co-criados só poderão ser mensurados a longo prazo. E por fim, é importante destacar que as contribuiç̧̃es do Design para a melhoria do projeto do tear, objetiva determinar novas metas e incentivar maior engajamento da comunidade com a Associação João Paulo II. 


\section{Referências Bibliográficas}

Associação João Paulo. Disponível em <https://www.ajoaopaulo.blogspot.com.br/> Acesso em 13 de Maio de 2016.

BORGES, A. Design + artesanato: o caminho brasileiro. p. 129, 2011.

CANCLINI, N. G. As culturas populares no capitalismo. p. 93. São Paulo, 1982.

GUEDELHA, E. J. S. A todo pano: uma experiência em design na produção artesanal de bolsas femininas. Monografia de graduação - Curso de Desenho Industrial - UFMA, 2008.

IDEO. The Field Guide to Human-Centered Design. A step-by-step guide that will get you solving problems like a designer. In Design Kit, 2017. (<http://www.designkit.org/resources/1)

MOZOTA, B. B. Gestão do design: usando o design para construir valor na marca e inovação corporativa. Porto Alegre: Bookman, 2011.

MOZOTA, B. B. Design Management: Using Design to build Brand Value and Corporate Innovation. Canada, Editora: Allworth Communications, Inc, 2003.

MUZAKE, S. e VILAMIL, D. C. 10 actions for a successful social designer to co-design. Product Service System 'PSS' Solutions in communities. p 7. Karlskrona, Sweden, 2012.

PATNAIK, D.; BECKER, R. Needfinding: The why and how of uncovering people's needs. Design Management Journal, v. 10, n. 617, p. 37-43, 1999.

SANDERS, E. B.-N.; STAPPERS, P. J. Co-creation and the new landscapes of Design. In: Make Tools, 2008.

(http://www.maketools.com/articlespapers/CoCreation_Sanders_Stappers_08_preprint.pdf(

SERAFIM, E. DESIGN E ARTESANATO NO BRASIL: reflexões sobre modelos de atuação do design junto a grupos de produção artesanal. Rio de Janeiro, 2011.

TACHIZAWA, T. Organizações não governamentais e Terceiro setor: criação de ONGs e estratégias de atuação. 2 ed. p.21. São Paulo, 2004. 